\title{
The Effects of Various Kinds of Form-Focused Instruction on Learners' Ability to Comprehend and Produce Polite Requests in English
}

\author{
Masahiro Takimoto
}

This study involving 60 Japanese learners of English investigated the effects of various kinds of form-focused instruction on learners' ability to comprehend and produce polite requests in English. Each treatment group received one of the following: (a) deductive instruction; (b) inductive instruction with problem-solving tasks; or (c) inductive instruction with structured input tasks. These tasks all involved explicit input-based instruction and were intended to test for differences in deductive versus inductive treatments. Treatment group performance was compared with that of a control group on a range of input-and output-based pretests, posttests, and follow-up tests. The results indicate that the three treatment groups performed significantly better than the control group, suggesting that in this study explicit input-based instruction was effective both deductively and inductively for learners' comprehension and production of English polite requests. There was also some indication that inductive treatment may be superior in the longer term.

Cette recherche implique 60 Japonais qui apprennent l'anglais et elle étudie les effets sur la capacité de comprendre et de produire des requêtes polies en anglais $q u$ 'ont diverses formes d'enseignement basé sur la forme. Chaque groupe expérimental a reçu : (a) de l'instruction déductive; (b) de l'instruction inductive avec des tâches de résolution de problèmes; ou (c) de l'instruction inductive avec des tâches input structurées. Toutes les tâches comportaient de l'instruction explicite basée sur l'input et étaient conçues pour évaluer les différences entre les méthodes déductives et inductives. Les performances des groupes expérimentaux ont été comparées à celles d'un groupe témoin, pour une gamme de prétests, posttests et suivis basés sur l'input et l'output. Les résultats indiquent que les trois groupes expérimentaux ont bien mieux performé que le groupe témoin, ce qui donne à penser que pour cette étude, l'instruction explicite basée sur l'input était efficace, tant sur le plan de la déduction que celui de l'induction, comme moyen de comprendre et de produire des requêtes polies en anglais chez les apprenants. De plus, quelques indicateurs permettent de conclure que l'instruction inductive est supérieure à long terme. 


\section{Introduction}

A fundamental question in second-language (L2) pragmatics concerns the kind of instructional approach that is most effective. Kasper and Rose (2002) argued that some form of awareness-oriented instruction is necessary because pragmalinguistic ${ }^{1}$ forms and sociopragmatic ${ }^{2}$ rules are often not salient enough for learners and that mere exposure to these rules in actual use does not help learners notice them. This suggests that it is necessary to explicitly teach appropriate L2 pragmatic realization patterns of speech acts such as requests, refusals, and apologies. The present study deals with requests.

Various intervention studies on teaching pragmatics have demonstrated that form-focused instruction is effective and that explicit instruction with some sort of input-enhancement method is more effective than implicit instruction (Takahashi, 2001; Tateyama, Kasper, Mui, Tay, \& Thananart, 1997). The issue here is whether explicit information should be provided before or after input enhancement activities so as to develop learners' pragmatic competence. In the study reported here, input-based explicit instruction is classified into deductive and inductive approaches.

\section{Deductive and Inductive Instruction}

Decoo (1996) elaborated five modalities along the deduction-induction continuum and four definitions for the inductive approach:

Modality A-Actual deduction.

Modality B-Conscious induction as guided discovery.

Modality C-Induction leading to an explicit "summary of behaviour."

Modality D-Subconscious induction on structured material.

Modality E-Subconscious induction on unstructured material. (p. 96)

The modalities relevant to this study are Decoo's modalities A and B.

Deductive instruction in this study is an application of modality A, whereas inductive instruction derives from modality B. This study clearly differentiates the inductive approach from implicit learning, in which there is neither rule presentation nor instructions to attend to particular forms. The deductive and inductive approaches employed, then, are both considered examples of explicit instruction, and they share a common objective: to enhance the salience of target forms in order to promote attention to and noticing of these structures. Such input enhancement (Sharwood Smith, 1993) can be implemented through structured input tasks or consciousnessraising tasks. Ellis (1997) explained that structured input tasks encourage learners to focus on the meaning of specific target forms and help them to intake directly the target features as implicit knowledge, whereas consciousness-raising tasks are designed to help learners to develop explicit knowledge about target features and indirectly to aid in facilitation of intake. 
Structured input tasks. VanPatten (1996) coined the term "processing instruction" and he (2004) argued that structured input activities in processing instruction push learners to process language forms using structured input that is manipulated in particular ways. This allows learners to depend on form to get the meaning, and/or it privileges form/structure in the input, so that learners have a better chance of attending to these elements. Studies on providing teacher-fronted explicit information before structured input tasks_-by VanPatten and Oikkenon (1996), Benati (2004), Farley (2004), and Wong (2004)—showed that proactive explicit information is not beneficial, but that structured input tasks by themselves are effective for improving learners' proficiency.

Ellis (1997) argued that structured input texts can be contrived such that (a) the target forms are presented frequently; (b) the meaning of the target forms is clear; and (c) understanding the target forms is essential for comprehending the whole text. He also explained a number of general principles for the design of structured input tasks; those most relevant to this study are: 1. "An interpretation activity consists of a stimulus to which learners must make some kind of response" (p. 155).

2. "The stimulus can take the form of spoken or written input" (p. 155).

3. "The response can take various forms (e.g., true/false, check a box, select the correct picture, draw a diagram, perform an action) but in each case the response will be either completely non-verbal or minimally verbal" (p. 155).

4. "The activities in the task can be helpfully sequenced to require first attention to meaning, then noticing the form and function of the grammatical structure and finally error identification" (p. 155).

5. "Interpretation tasks should require learners to make a personal response (i.e., relate the input to their own lives) as well as a referential response" (p. 159).

This study employs Ellis's (1997) structured input tasks, defined as activities designed to invite learners to engage in intentional learning by consciously noticing how a target pragmatic expression is used in input specially contrived to contain numerous exemplars of the structure.

Problem-solving tasks. In this study the term problem-solving task is used in place of the term consciousness-raising task because teachers can control only their manipulation of the input, not its effect on learners' consciousness. The problem-solving tasks in this study are defined as tasks in which learners are provided with L2 data that they need in order to perform some operation on, or with in order to arrive at an explicit understanding of, some linguistic property or properties of the target language. Ellis (2003) identified the main characteristics of problem-solving tasks.

1. There is an attempt to isolate a specific linguistic feature for focused attention. 
2. The learners are provided with data that illustrate the target feature and they may also be provided with an explicit rule describing or explaining the feature.

3. The learners are expected to use intellectual effort to understand the target feature.

4. Learners may be optionally required to verbalize a rule describing the grammatical structure. (p. 163)

Some studies investigated the effectiveness of problem-solving tasks in L2 grammar teaching. Fotos and Ellis (1991) and Fotos (1994) examined the effects of problem-solving tasks-including teacher-fronted grammar explanations as compared with the effects of problem-solving tasks without teacher-fronted grammar explanations-by studying two groups of Japanese EFL learners. Fotos and Ellis indicated that both groups made significant gains on a grammaticality judgment test, whereas Fotos found no statistically significant difference between the two groups. Based on the results of these two studies, problem-solving tasks are concluded to be at least potentially useful activities because they may promote noticing and proficiency gains.

\section{Intervention Studies of L2 Pragmatics}

A number of intervention studies in pragmatics teaching have contrasted the effectiveness of explicit and implicit learning, with results indicating a general trend in support of explicit learning (Takahashi, 2001; Tateyama et al., 1997), although some studies (Martínez-Flor \& Fukuya, 2005) found input enhancement alone as effective as explicit metapragmatic information. These studies show that the target pragmatic features can be most effectively learned when taught explicitly along with some sort of input enhancement method.

Of all the intervention studies, only that of Rose and $\mathrm{Ng}$ (2001) was conducted in the deductive/inductive framework proposed by Decoo (1996). They investigated the effectiveness of the deductive and inductive approach in teaching compliments and compliment responses. The participants, 44 undergraduate students in Hong Kong, were assigned to two experimental groups and one control group. Both experimental groups followed the same procedure with one exception: the inductive group was not provided with any metapragmatic information about the target structures, but was exposed to film segments and additional examples of the structures and provided with questions to guide their discovery about the target features. The deductive group, on the other hand, was provided with metapragmatic information before working on analyzing compliment and compliment response data. Results showed that both inductive and deductive instruction led to gains in pragmalinguistic proficiency, but that only deductive instruction effectively developed sociopragmatic proficiency. Pos- 
sible reasons for these findings are first, that participants were advanced learners who could benefit from either type of instruction; second, that the syntactic form of compliments was a somewhat easy pragmalinguistic feature; and third, that there were significant differences on the pretests, which did not establish equal starting points for all participant groups. This study did provide some evidence that instruction in L2 English polite requests can make a difference, but certain problematic issues encouraged me to reexamine the effectiveness of deductive and inductive approaches to teaching L2 polite requests in English.

\section{The Present Study}

Intervention studies in pragmatics teaching have indicated that target pragmatic features can be most effectively learned when taught explicitly along with some sort of input enhancement. However, when and how input may be most beneficially enhanced, and in addition when and how metapragmatic information is best provided, are controversial issues. Only one study (Rose \& Ng, 2001) on interlanguage pragmatics (ILP) investigated the effectiveness of the deductive and inductive approaches in line with Decoo's (1996) modalities. The lack of recent studies in this field suggests that more studies in the field of ILP are required. Consequently, the following specific research question is investigated in this study: What are the effects of different kinds of form-focused instruction-deductive instruction, inductive instruction with problem-solving tasks, and inductive instruction with structured input tasks—on participants' ability to comprehend and produce polite requests in English?

\section{Participants}

Participants were solicited through employment advertisements by a major agency in Japan in their weekly magazine and on the Internet. They were not told in advance that English lexical and syntactic downgraders would be taught in the study. Participants were screened by means of their Test of English for International Communication (TOEIC) scores, which they were required to submit, and only individuals with intermediate English proficiency level (TOEIC scores of 500-700) were chosen.

The 60 participants had studied English from five to 22 years, had Japanese as their first language, and were in the 18-40 age range. They were assigned to one of four groups (three treatment groups and one control group) on a first-come, first-served basis. The three treatment groups were deductive instruction (DI) $(n=15)$, inductive instruction with problem-solving tasks (IP) $(n=15)$, and inductive instruction with structured input tasks (IS) $(n=15)$. 


\section{Target Structures}

According to the studies related to learners' request strategies conducted by Hill (1997) and Takahashi (1998, 2001), many Japanese learners of English appear to lack L2 pragmalinguistic knowledge of how an English request can be mitigated with the use of syntactic downgraders such as aspect and tense and lexical/phrasal downgraders such as subjectivizers and downtoners. Therefore, this study focuses on teaching two syntactic downgraders, aspect and tense, and two lexical/phrasal downgraders, downtoners and subjectivizers, in English requests.

Lexical/phrasal downgraders soften the imposition of a request by means of modifying the Head Act internally through lexical/phrasal choices, whereas syntactic downgraders modify the Head Act internally by means of mitigating the imposition force of a request through syntactic choices (BlumKulka, House, \& Kasper, 1989). A list of internal modifiers (summarized from Blum-Kulka, House, \& Kasper, 1989) is shown in Table 1.

\section{Instructional Treatments}

Each teaching session for the four groups lasted 40 minutes, and the instructor gave all directions in Japanese during instruction. Sessions were conducted twice a week by the same instructor for two weeks at a major English conversation school in Osaka. The three instructional treatments were three types of explicit instruction; these were matched for target pragmatic structures, and all four groups were matched for time on task. The first class for all treatment groups was on lexical/phrasal downgraders in English requests, the second on syntactic downgraders, the third on a review of the first class, and the fourth on a review of the second class (see Table 2).

The DI treatment consisted of two components: (a) a teacher-fronted explicit explanation of the relationship between the form of specific downgraders and the meanings they convey, and (b) structured input tasks (see Appendix A). The participants were instructed not only to read or listen to the dialogues, but also to make a decision concerning the appropriateness

Table 1

\begin{tabular}{ll}
\hline Internal modifier & Example \\
\hline $\begin{array}{l}\text { Internal syntactic downgraders } \\
\text { Aspect (durative aspect marker) }\end{array}$ & $\begin{array}{l}\text { I am wondering if you could lend me a book. } \\
\text { Iense }\end{array}$ \\
$\begin{array}{ll}\text { Internal lexical and phrasal downgraders to ask you to come here. } \\
\text { Subjectivizer }\end{array}$ & $\begin{array}{l}\text { I wonder if you could come here. } \\
\text { l'm afraid you are going to have to move your } \\
\text { desk. }\end{array}$ \\
Downtoner & Could you possibly lend me your textbook? \\
\hline
\end{tabular}


Table 2

Treatment Features of Each Group

\begin{tabular}{|c|c|}
\hline Group & Treatment \\
\hline Deductive instruction (DI) $(n=15)$ & $\begin{array}{l}\text { Proactive explicit information ( } 10 \text { minutes) }+ \\
\text { structured input tasks ( } 30 \text { minutes) }\end{array}$ \\
\hline $\begin{array}{l}\text { Inductive instruction with } \\
\text { problem-solving tasks (IP) }(n=15)\end{array}$ & Problem-solving tasks only (40 minutes) \\
\hline $\begin{array}{l}\text { Inductive instruction with structured } \\
\text { input tasks (IS) }(n=15)\end{array}$ & Structured input tasks only (40 minutes) \\
\hline Control group $(n=15)$ & TOEIC reading comprehension exercises (40 minutes) \\
\hline
\end{tabular}

of the requests. In each lesson, the DI participants were given handouts with a brief summary and with examples of the target structures in English. The instructor took approximately 10 minutes to read the summary and examples aloud in English and to provide an explanation in Japanese. Then the DI participants were given handouts with three referential activities and three affective activities. In the referential activities, they read each situation and dialogue and selected the more appropriate request form out of two offered for each underlined part. They then listened to a recording of the dialogue and indicated the request used in the dialogue. In the affective activities, participants were asked to read each situation and dialogue and then listen to a recording of the dialogue. Second, they were instructed to rate the appropriateness of each underlined request in accordance with their opinion on a five-point Likert scale.

The IP treatment involved only one component, problem-solving tasks (see Appendix B). The tasks include the following activities: (a) making a form-comparison, (b) answering analysis questions, and (c) listing ways that the requests in two dialogues differed. In each lesson, participants were instructed to form small groups of two to four and were given handouts that contained six English dialogues. Participants read each situation and dialogue, and then listened to it. They then wrote the underlined requests in two of the dialogues and compared the underlined request forms in the two dialogues. Then they were asked to find and write in Japanese the differences between the two requests. The groups then answered three analysis questions about the relationship between the two characters, the difficulty of the requests, and the appropriateness of the requests in both dialogues. Finally, they were instructed to list ways that the requests differed between dialogues. After answering the analysis questions and making the list in groups, each group leader was asked to present to the class in English the answers to the analysis questions and the list of differences.

The IS treatment consisted only of engaging in the same structured input activities as the DI group. Whereas it took the DI group 30 minutes to 
complete the structured input activities, it took the IS group approximately 40 minutes to complete the activities.

Lessons for the control group $(n=15)$ were designed to help participants perform well on the TOEIC, and participants in this group engaged in TOEIC reading comprehension exercises. Participants in the control group were not exposed to the target structures during the lessons.

\section{Testing Instruments and Procedures}

This study used pretests, posttests, and follow-up tests. The pretests were conducted two to three days before the instructional treatment, the posttests eight to nine days after the treatment, and the follow-up tests in the fourth week following instruction. The posttests were administered eight to nine days after the treatment because any treatment tends to produce a positive effect immediately afterward, so it is difficult to distinguish one treatment from another in terms of the effect right after the treatment.

Each test consisted of two output-based tests-such as an open-ended discourse completion test (OPDCT) and a role-play test (RP) - and two input-based tests such as a listening test (LT) and an acceptability judgment test (AJT). The OPDCT, RP, and AJT consisted of 20 situations, whereas the LT consisted of 15 situations. All situations had one speech act (request), and three sociolinguistic variables were controlled: Power (the status of the speaker with respect to the hearer), degree of Imposition (the difficulty of hearer's performance of the request made by the speaker), and Distance (the relationship between the speaker and the hearer). There is a correlational relationship between the degree of Imposition and the use of downgraders, in that a higher degree of Imposition, combined with Power and Distance, results in the use of more downgraders. Therefore, this study focuses on high Imposition situation (HI) items combined with Power and Distance. One sample item is shown below; it may be analyzed as [+imposition], [.power], [+distance], where [+] means "more" and [.] means "less."

You are writing a difficult paper for Professor Hill. You need some help with the paper but Professor Hill is away for a month. A friend of yours has suggested you go and see Professor Watson. Although you do not know Professor Watson and Professor Watson is extremely busy, you have decided to ask Professor Watson to look through your long paper before you hand it in the next day. What would you ask Professor

Watson? (based on Takahashi, 1998, 2001)

The situations validated by Hudson, Detmer, and Brown (1992, 1995), Hill (1997), and Takahashi $(1998,2001)$ were modified and used, incorporating a range of interlocutors related to two contexts: student life outside school and student life in school. 
Three versions each (A, B, and C) of the OPDCT, RP, LT, and AJT were developed, and were all counterbalanced for order of presentation of the same situations across the pre- and posttest sessions. Three versions were adopted so that any learning effect would be minimized.

The pretests, posttests, and follow-up tests were conducted in the following order: the OPDCT, RP, LT, and AJT. The two input-based tests were moved to the end because of a concern that they might function as a list of possible responses that would provide participants with some hints on the other tests. The participants were asked to complete the four tests within two hours and only the LT had a time limit (2 seconds per question). Examples of the four tests are given in Appendix C.

Open-ended discourse completion test (OPDCT). The OPDCT required participants to read short descriptions in English of 20 situations and write in English what they would say in each situation. Participants were given a Japanese supplement to use. Although there was no time limit for completing the OPDCT, most participants took 30-45 minutes. The appropriateness of the request forms was rated by two native English speakers on a six-point Likert scale, where $0=n o t$ appropriate at all and $5=$ completely appropriate. An answer that reflected mastery of downgraders in participants' requests was given 5 points. Moreover, partial points (i.e., 1, 2, 3, 4) were given, and the more syntactic and lexical downgraders participants used, the higher the score they obtained. The test contained 20 items, the maximum score being100.

Role-play test $(R P)$. The RP consisted of short descriptions of 20 situations written in English with a Japanese supplement, and participants were instructed to play particular roles with the researcher in those situations. The researcher, a nonnative speaker of English, was chosen as an interlocutor to give examinees a stress-free testing situation interacting with another nonnative speaker rather than a native speaker examiner. This procedure presumably elicits examinees' best performance (Ellis, 2003). Before the roleplay, participants were given role cards describing the situations and their roles and were required to start the role-play by asking for something from their interlocutors. Participants on average took two to three minutes to prepare for each role-play, which was tape-recorded, and their individual performance was rated on the appropriateness of request forms by two native speakers of English on a six-point Likert scale, where $0=$ not appropriate at all and $5=$ completely appropriate. Spoken sentences in each role-play that reflected mastery of downgraders in participants' requests were given 5 points. Moreover, partial points were given, and the more syntactic and lexical downgraders participants used, the higher the score they obtained. The test contained 20 items, the maximum score being 100 .

Listening test (LT). The LT consisted of 15 situations and required the participants to listen to a pragmatic performance between a Japanese univer- 
sity student and native speakers of English and then to score the appropriateness of the Japanese university student's request forms on a six-point Likert scale, where $0=n o t$ appropriate at all and 5=completely appropriate. The test was conducted with an audiorecording of the dialogue and a timing constraint of two seconds to rate the appropriateness of the requests. When a participant rated a request appropriately in line with English native speakers' baseline data, 5 points were given. Partial points were not given, and participants got either 0 or 5 points. The test contained 15 items, the maximum score being 75 .

Acceptability judgment test (AJT). The AJT involved participants using a computer to read written English descriptions of 20 situations, with a Japanese supplement. Participants were then presented with a series of isolated requests and instructed to score the first possible request on an 11-point Likert scale, where $0=$ not appropriate at all and $10=$ completely appropriate and to score subsequent responses with proportionally higher or lower numbers in line with their degree of perceived acceptability. An 11-point Likert scale was used because a broader range in scale encourages more precision in respondents' judgments (Hatch \& Lazarton, 1991). When a participant gave the most appropriate request, the highest score of 5 points was given in accordance with English native speakers' baseline data. Partial points were not given, and participants got either 0 or 5 points. The test contained 20 items, the maximum score being 100 .

\section{Reliability}

Interrater reliability was estimated by examining the correlation coefficients between the raters' scores. The correlation coefficients for the OPDCT and RP were .995 and .994 respectively.

To calculate the reliability of each instrument, Cronbach alpha reliability estimates were calculated for each (see Table 3). Although the internal consistency reliability estimates for the pragmatics tests were fairly high, the reliability of the LT was low. This was due to five problematic items, which when deleted yielded relatively high levels of reliability in the LT.

Table 3

Cronbach Alpha Reliability Estimates for Each Test

\begin{tabular}{lccc}
\hline Test & Version $A$ & Version $B$ & Version C \\
\hline OPDCT & .942 & .919 & .911 \\
RP & .935 & .950 & .915 \\
LT & .791 & .714 & .801 \\
AJT & .868 & .858 & .988 \\
\hline
\end{tabular}


Table 4

Factor Analysis for the OPDCT, RP, LT, and AJT

\begin{tabular}{llll}
\hline Variable & Factor 1 & Factor 2 & $h^{2}$ \\
\hline OPDCT & .949 & .237 & .957 \\
RP & .956 & .193 & .952 \\
LT & .405 & .751 & .728 \\
AJT & .087 & .920 & .853 \\
Proportion of variance & .497 & .376 & .873 \\
\hline
\end{tabular}

Validity

Construct validity was examined on the basis of factor analysis procedures (see Table 4). The results show that Factors 1 and 2 appear to differ, but this result is probably related to the test method, as the OPDCT and RP tests use productive item types (i.e., they require participants to produce written or oral language), whereas the AJT and LT tests assess receptive knowledge. Thus Factor 1 might be considered a productive-language factor and Factor 2 a receptive-language factor. Notice, however, that the LT also loaded fairly heavily on Factor 1 (at .405) along with the OPDCT (at .949) and the RP (at .956). This may be because the LT, OPDCT, and RP are paper-based tests, whereas the AJT is a computer-based test, possibly causing the LT load on Factor 1 as well. Therefore, the results of the factor analysis provide some evidence for construct validity.

\section{Results}

This section examines the results for each testing instrument more closely. In the data analysis a Bonferroni adjustment was employed in order to maintain an approximate experiment-wide .05 alpha level. In other words, the overall alpha level was set at .05, but with four group comparisons (the OPDCT, RP, LT, and AJT). Therefore, .05 was divided by the number of comparisons (four), resulting in a $p$ value of .0125 for the individual statistical decisions.

Open-ended discourse completion test results. The results of a two-way repeated-measures ANOVA performed on the raw scores in the OPDCT show a significant main effect for Instruction, $F(3,56)=99.92, p<.001$; a significant main effect for Time, $F(3,56)=583.57, p<.001$; and a significant interaction effect between Instruction and Time, $F(9,56)=48.64, p<.001$.

The results displayed in Figure 1 show that although there are no statistically significant differences among the four groups on the pretest scores$F(3,56)=1.06, p=.373$ - the three treatment groups made gains from the pretests to the posttests and the follow-up tests $-F(3,56)=127.12, p<.001 ; F(3$, $56)=178.42, p<.001$ - and the positive effects for the three treatments were maintained: there were no significant differences between the posttests and 
follow-up tests, $F(2,42)=.58, p=.566$. Therefore, the results suggest a positive effect of Instruction. Furthermore, the interaction shows the relative superiority of the three treatment groups over the control group, with no crossovers between the three treatment groups and the control group after the treatments.

Role-play test results. The results of a two-way repeated-measures ANOVA conducted on the raw scores in the RP show a significant main effect for Instruction, $F(3,56)=83.93, p<.001$; a significant main effect for Time, $F(3$, $56)=502.61, p<001$; and a significant interaction effect between Instruction and Time, $F(9,56)=33.88, p<.001$.

The results displayed in Figure 2 indicate that although there are no statistically significant differences among the four groups on the pretest scores- $F(3,56)=.54, p=.654$ - the three treatment groups made gains from the pretests to the posttests and the follow-up tests- $F(3,56)=161.05, p<.001$; $F(3,56)=133.90, p<.001$ - and the positive effects for the three treatments were maintained; there were no significant differences between the posttests and follow-up tests: $F(2,42)=161.05, p=.564$. Accordingly, the results suggest a positive effect of Instruction, and the interaction shows the relative superiority of the three treatment groups over the control group, with no crossovers between the three treatment groups and the control group after the treatments.

Listening test results. The results of a two-way repeated-measures ANOVA on the raw scores show a significant main effect for Instruction, $F(3,56)=$

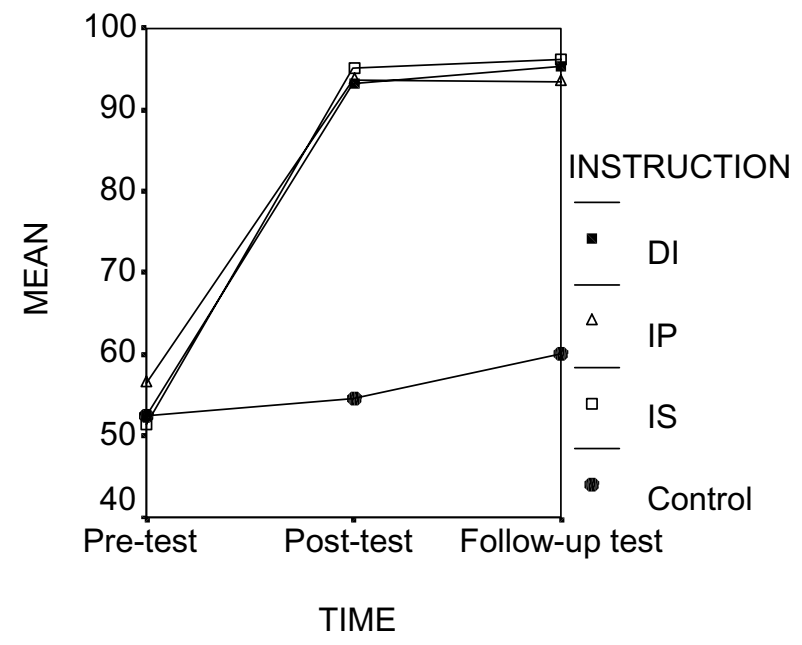

Figure 1. Interaction plot for the OPDCT.

Note. DI=Deductive instruction; $\mathrm{IP}=$ Inductive instruction with problem-solving tasks; IS=Inductive instruction with structured input tasks. 
27.48, $p<.001$; a significant main effect for Time, $F(3,56)=81.27 p<.001$; and a significant interaction effect between Instruction and Time, $F(9,56)=7.97$, $p<.001$.

Results displayed in Figure 3 reveal that although there are no statistically significant differences among the four groups on the pre-test scores- $F(3$, $56)=1.91, p=.139$ - the three treatment groups made gains from the pretests to the posttests and the follow-up tests: $F(3,56)=33.98, p=.000 ; F(3,56)=36.18$, $p<.001$. However, Figure 3 shows that unlike the IP and IS groups, the DI group did not maintain the positive effects between the posttest and followup test: $F(2,42)=8.36, p=.001$. A separate ANOVA performed on the followup test scores shows a significant difference $-F(2,42)=13.10, p<.001-$ in how the three treatment groups performed on this test. Although the DI group did not retain the positive effects between the posttest and follow-up test, the results suggest a positive effect of Instruction. Furthermore, the interaction shows the relative superiority of the three treatment groups over the control group, with no crossovers between the three treatment groups and the control group after the treatments.

Acceptability judgment test results. The results of a two-way repeatedmeasures ANOVA on the raw scores indicate a significant main effect for Instruction, $F(3,56)=7.32, p<.001$; a significant main effect for Time, $F(3$, $56)=43.07, p<.001$; and no significant interaction effect between Instruction and Time, $F(9,56)=3.21, p<.006$.

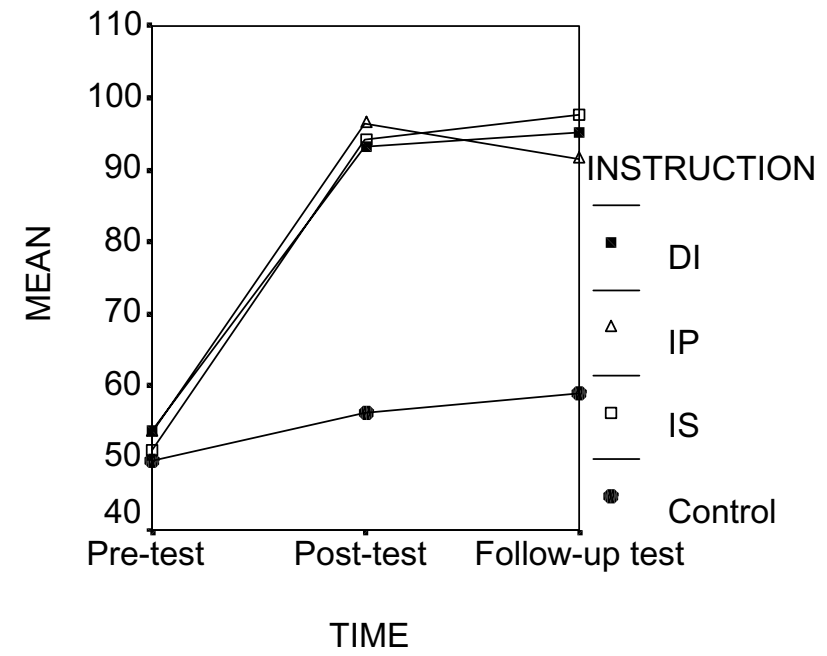

Figure 2. Interaction plot for the RP.

Note. DI=Deductive instruction; IP=Inductive instruction with problem-solving tasks; IS=Inductive instructions with structured input tasks. 
The results displayed in Figure 4 show that although there are no statistically significant differences among the four groups on the pretest scores$F(3,56)=.33, p=.801$ - the three treatment groups made gains from the pretests to the posttests and the follow-up tests- $F(3,56)=16.56, p<.001 ; F(3$, $56)=14.69, p<.001$-and the positive effects for the three treatments were maintained; there were no significant differences between the posttests and follow-up tests: $F(2,42)=3.06, p=.058$. Therefore, the results suggest a positive effect of Instruction, and the three treatment groups performed significantly better than the control group.

\section{Discussion}

The research question about the relative effects of each instructional treatment was investigated, and it was found that the DI, IP, and IS groups performed significantly better than the control group, and the DI, IP, and IS groups performed equally well on the OPDCT, RP, LT, and AJT. However, the DI group did not perform as well as the IP and IS groups on the LT follow-up test. The question arises, then: Why did the DI group perform as well as the IP and IS groups on the immediate LT but not as well on the follow-up version of the LT, when no such difference was evident on any of the other tests? Any answers to this question must be speculative as no information about the psycholinguistic processing involved in either the treatments or the test is available. However, the LT differs from the other tests in that it asks for on-line processing. As such tests rely heavily on

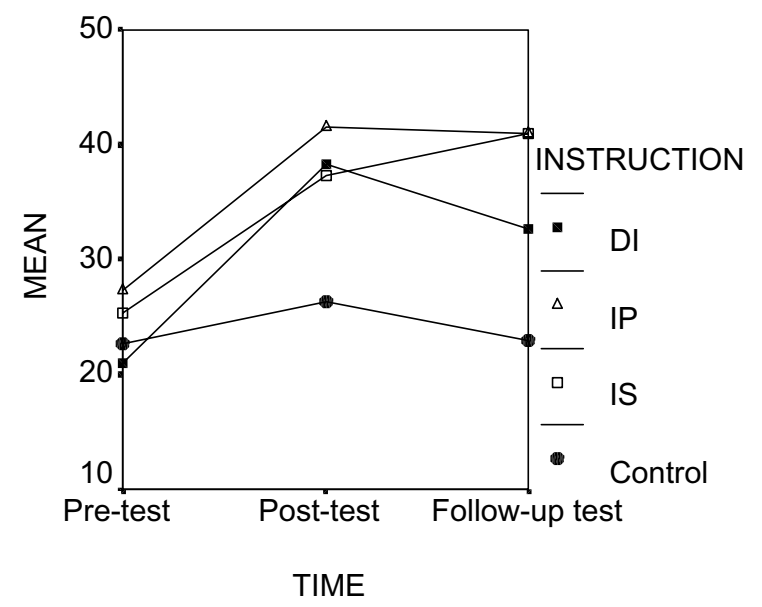

Figure 3. Interaction plot for the LT.

Note. DI=Deductive instruction; IP=Inductive instruction with problem-solving tasks; IS=Inductive instruction with structured input tasks. 
working memory, participants must process and respond to the stimuli rapidly, and relatively efficient processing is required. In the deductive treatment, participants were simply given explicit information, whereas in the inductive treatments they had to discover the underlying rules themselves. It appears that the explicit knowledge formed by the participants in the deductive treatment was weakly established and was not accessible during the follow-up test, whereas the explicit knowledge produced by the participants in the inductive treatment was more firmly acquired and thus more easily accessed by all of the tests. In addition, it may also be supposed that participants using the inductive approach were better able to process and store information in working memory about the target features.

The two types of input-based task employed in this study were problemsolving tasks and structured-input tasks. It can be assumed that inductive instruction is effective when combined with either problem-solving tasks or structured input tasks, and there are three possible reasons for this. First, the two tasks are not drills. Drills are form-only activities that usually do not require learners to comprehend the language, but rather just to produce a structure or form correctly. The underlying belief is that drill use for language-learning results in mechanical habit formation and that acquisition is based on the correct production of the structure or form. However, Wong and VanPatten (2003) argue that mechanical habit formation does not promote language-learning. In addition, they suggest that output-based mechanical exercises are not necessary for language acquisition and that input-dependent meaning-based activities should supplant them.

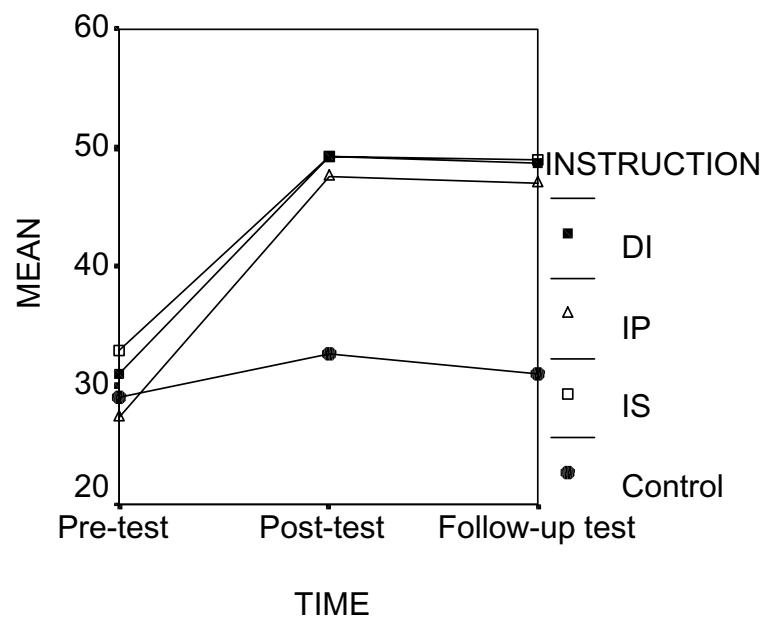

Figure 4. Interaction plot for the AJT.

Note. DI=Deductive instruction; IP=Inductive instruction with problem-solving tasks; IS=Inductive instruction with structured input tasks. 
Second, the effectiveness of input-based tasks is related to participants' attention to the form of the input they have received. Although the two treatments involved different tasks, they may have made the target structures equally salient. The participants in the IP group were instructed to pay attention to the highlighted requests in two dialogues, copying them and comparing the request in one dialogue with that in the other. Then they were instructed to find and discuss the underlying rules about the target structures. In contrast, the participants in the IS group were asked to pay attention to the target linguistic forms and the meanings they conveyed during referential and affective activities. In the referential activities, the participants were instructed to choose the more appropriate request form from two that were offered for each highlighted part, whereas in the affective activities the participants were asked to rate the level of appropriateness of each bold-faced underlined request in accordance with their belief. Schmidt (1995) stated that when learners continue to notice a feature in subsequent communicative input, acquisition of that feature may take place.

The third possible reason for the effectiveness of the two types of inputbased tasks involves processing meaning. In the IP treatment, the problemsolving tasks were designed not only to develop explicit knowledge, but also to stimulate internal mechanisms involving the processing of meaning, where participants had an opportunity to talk meaningfully about the target features. Wong and VanPatten (2003) suggest that when learners encounter input in structured input tasks, their internal mechanisms begin to make connections between the target features and the meaning they convey. They further suggest that learners' internal mechanisms deliver data to other internal mechanisms that form the linguistic system. In short, when participants focus more on the meaning of the target feature, it possibly stimulates their perceptual and mental processing, and they are likely to process the target form at a deeper level.

The main focus of the study reported here is to examine the effectiveness of the theoretical claims of skill-learning theory and of information-processing theory for teaching polite requests in English. The results of the present study do not lend support to the theoretical claims of skill-learning theory, but they do support the theoretical claims of information-processing theory. Skill-learning theory claims that a particular skill is learned as a result of practice. Anderson's (1983) Adaptive Control of Thought theory considers language-learning like any other kind of skill-learning in that it involves a progression from declarative knowledge to procedural knowledge through extensive practice in using the L2. Declarative knowledge is not automatic, whereas procedural knowledge is. According to skill-learning theory, practice through input-based instruction develops only participants' ability to comprehend target features and does not serve to develop their ability to produce target structures. However, in this study, practice through input- 
based instruction did appear to develop participants' ability to comprehend and produce target structures. This accords with information-processing theory, which claims that input-based instruction will serve to develop participants' ability both to comprehend and to produce target features drawing on the same underlying knowledge source. The three input-based treatment groups performed significantly better than the control group not only on the two input-based tests (the LT and AJT), but also on the two output-based tests (the OPDCT and RP), which implied that the input-based treatments developed the same underlying knowledge source, which was called on in both comprehension and production. According to Robinson's (1995) review of information-processing theories, general cognitive mechanisms process information in input to achieve a mental representation of target structures. This knowledge is then accessed through other cognitive mechanisms and enables participants to comprehend and produce target structures.

\section{Conclusion}

Having examined the effects of various kinds of form-focused instruction, this study can contribute to language pedagogy because the findings have practical applications, not only for English as a foreign language (EFL) classrooms in Japan-where learning English pragmatics rather than English grammar is becoming a more important area of instruction-but also for Canadian classes where teachers use inductive form-focused instruction to teach pragmatics.

The results of the present study indicate that inductive instruction is effective when combined with problem-solving tasks or structured input tasks specifically when the emphasis is on form and meaning. Thus the implication for teachers is that they should be aware that effective learning occurs when tasks provide learners with opportunities to process both the form and the meaning of the target features.

The present study suggests several limitations that future research should consider. First, the participants were assigned to groups on a first-come, first-served basis, and this may have had an effect on the results, because one might suppose the first to respond would be more motivated. Second, the participants ranged in age from 18 to 40 , and this may have had an effect on their interpretation of situations. Therefore, the present study might have observed the participants' improvement more accurately if it had randomly assigned participants with a more similar age range across groups. Third, the tasks were designed for student learners, and so not all learners in the study would be equally familiar with the contexts used in teaching and testing.

Even with such shortcomings, this study has made a contribution to our understanding that an effective way of teaching L2 pragmatics leads to a positive outcome, especially in the Japanese EFL context. I hope that the 
results of the present study will provide researchers and teachers with clearer guidelines for effective form-focused strategies for teaching L2 pragmatics to both Japanese and Canadian learners.

Notes

${ }^{1}$ The knowledge of the strategies for realizing speech intentions and linguistic items used to express these intentions is called knowledge of pragmalinguistics (Leech, 1983; Thomas, 1983).

${ }^{2}$ The knowledge of the social conditions governing language is named knowledge of sociopragmatics (Leech, 1983; Thomas, 1983).

\section{Acknowledgments}

I am very grateful to Professor Rod Ellis, Professor James Brown, and Professor David Beglar for their skillful guidance and support.

\section{The Author}

Masahiro Takimoto is an associate professor in Department of English Language and Cultural Studies at Faculty of Humanities at Tezukayama University, Nara, Japan. His research interests are in the roles of instruction in learning second-language (L2) pragmatics and the relationship between development of L2 grammatical competence and L2 pragmatic competence.

\section{References}

Anderson, J.R. (1983). The architecture of cognition. Cambridge, MA: Harvard University Press.

Benati, A. (2004). The effects of structured input activities and explicit information on the acquisition of Italian tense. In B. VanPatten (Ed.), Processing instruction: Theory, research, and commentary (pp. 207-255). Mahwah, NJ: Erlbaum.

Blum-Kulka, S., House, J., \& Kasper, G. (1989). Cross-cultural pragmatics: Requests and apologies. Norwood, NJ: Ablex.

Decoo, W. (1996). The induction-deduction opposition: Ambiguities and complexities of the didactic reality. IRAL-International Review of Applied Linguistics in Language Teaching, 34, 95-118.

Ellis, R. (1997). SLA research and language teaching. Oxford, UK: Oxford University Press.

Ellis, R. (2003). Task-based language learning and teaching. Oxford, UK: Oxford University Press

Farley, A.R. (2004). Processing instruction and the Spanish subjunctive: Is explicit information needed? In B. VanPatten (Ed.), Processing instruction: Theory, research, and commentary (pp. 227-239). Mahwah, NJ: Erlbaum.

Fotos, S. (1994). Integrating grammar instruction and communicative language use through grammar consciousness-raising tasks. TESOL Quarterly, 28, 323-351.

Fotos, S.S., \& Ellis, R. (1991). Communicating about grammar: A task-based approach. TESOL Quarterly, 25, 605-628.

Hatch, E., \& Lazaraton, A. (1991). The research manual: Design and statistics for applied linguistics. New York: Newbury House.

Hill, T. (1997). The development of pragmatic competence in an EFL context. Unpublished doctoral dissertation, Temple University, Japan.

Hudson, T., Detmer, E., \& Brown, J.D. (1992). A framework for testing cross-cultural pragmatics. Honolulu, HI: University of Hawai'i Press.

Hudson, T., Detmer, E., \& Brown, J.D. (1995). Developing prototypic measures of cross-cultural pragmatics. Honolulu, HI: University of Hawai'i Press.

Kasper, G.,\& Rose, K. (2002). The role of instruction in learning second language pragmatics. Language Learning, 52(S1), 237-273.

Leech, G.N. (1983). Principles of pragmatics. London: Longman. 
Martínez-Flor, A., \& Fukuya, Y.J. (2005). The effects of instruction on learners' production of appropriate and accurate suggestions. System, 33, 463-480.

Robinson, P. (1995). Attention, memory, and the "noticing" hypothesis. Language Learning, 45, 283-331.

Rose, K.R., \& Ng, C. (2001). Inductive and deductive teaching of compliments and compliment responses. In K.R. Rose \& G. Kasper (Eds.), Pragmatics in language teaching (pp. 145-170). New York: Cambridge University Press.

Schmidt, R. (1995). Consciousness and foreign language learning: A tutorial on the role of attention and awareness in learning. In R. Schmidt (Ed.), Attention and awareness in foreign language learning (pp. 1-64). Honolulu, HI: University of Hawai'i Press.

Sharwood Smith, M. (1993). Input enhancement in instructed SLA: Theoretical bases. Studies in Second Language Acquisition, 15, 165-179.

Takahashi, S. (1998). Quantifying requestive imposition: Validation and selection of situation for L2 pragmatic research. Studies in Languages and Cultures, 9, 135-159.

Takahashi, S. (2001). The role of input enhancement in developing interlanguage pragmatic competence. In K. Rose \& G. Kasper (Eds.), Pragmatics in language teaching (pp. 171-199). New York: Cambridge University Press.

Tateyama, Y., Kasper, G., Mui, L., Tay, H., \& Thananart, O. (1997). Explicit and implicit teaching of pragmatic routines. In L. Bouton (Ed.), Pragmatics and language learning, monograph series Vol. 8 (pp. 163-178). Urbana-Champaign, IL: Division of English as an International Language, University of Illinois, Urbana-Champaign.

Thomas, J. (1983). Cross-cultural pragmatic failure. Applied Linguistics, 4, 91-112.

VanPatten, B. (1996). Input processing and grammar instruction in second language acquisition. Norwood, NJ: Ablex

VanPatten, B. (2004). Input processing in SLA. In B. VanPatten (Ed.), Processing instruction: Theory, research, and commentary (pp. 5-31). Mahwah, NJ: Erlbaum.

VanPatten, B., \& Oikkenon, S. (1996). Explanation versus structured input in processing instruction. Studies in Second Language Acquisition, 18, 495-510.

Wong, W. (2004). Processing instruction in French: The roles of explicit information and structured input. In B. VanPatten (Ed.), Processing instruction: Theory, research, and commentary (pp. 187-205). Mahwah, NJ: Erlbaum.

Wong, W., \& VanPatten, B. (2003). The evidence is IN: Drills are OUT. Foreign Language Annals, $36,403-423$.

\section{Appendix A}

Sample Activities Used in Structured Input Tasks

Referential activity: Read the following situation and the dialogue and choose the more appropriate request form out of two offered for each underlined part and indicate your choice by circling (a) or (b). Then listen to an oral recording of the dialogue and indicate whether the actual request used in the dialogue is (a) or (b).

Situation: Yuka is about to start her car when she notices that her car battery has gone flat. She needs to go to school now and she does not have any other means but to ask her landlord, $\mathrm{Mr}$. Brown, whom she has never spoken to before, to give her a ride to school. Her landlord is extremely busy, but she decides to ask her landlord to drive her to school.

Brown: Hello.

Yuka: Hi, you are Mr. Brown, aren't you?

Brown: That's right.

Yuka: I'm a tenant next door. My car battery has just gone flat and I can't start my car. I really need to get to school. 1. (a) I was just wondering if I could by any chance get a lift; (b) I am just wondering if I could by any chance get a lift. 


\section{Appendix B}

\section{Sample Activities Used in Problem-Solving Tasks}

Read the dialogue $\mathrm{A}$ and the dialogue $\mathrm{B}$ and answer the following questions.

Dialogue A.

Situation: Yuka is about to start her car when she notices that her car battery has gone flat. She needs to go to school now and she does not have any other means but to ask her neighbor,

James, whom she knows well, to give her a ride to school. She sees her neighbor go out by car and she decides to ask her neighbor to drive her to school.

James: $\quad$ Hi, Yuka.

Yuka: $\quad \mathrm{Hi}$, Jim. My car battery has just gone flat and I can't start my car. I really need to get to school. (a) Could I have a lift ?

James: $\quad$ Sure. Get in.

Dialogue B.

Situation: Yuka is about to start her car when she notices that her car battery has gone flat. She needs to go to school now and she does not have any other means but to ask her landlord, Mr. Brown, whom she has never spoken to before, to give her a ride to school. Her landlord is extremely busy, but she decides to ask her landlord to drive her to school.

Brown: Hello.

Yuka: Hi, you are Mr. Brown, aren't you?

Brown: That's right.

Yuka: $\quad$ I am a tenant next door. My car battery has just gone flat and I can't start my car. I really need to get to school. (a)' I wonder if I could get a lift.

Brown: Well, actually, I am really busy helping other tenants moving into this apartment. So, I can't really help you.

1. Write up the requests Yuka makes in the dialogue $\mathrm{A}$ and the dialogue $\mathrm{B}$ in the table below and also comment on the differences between the two.

a.

$$
\text { Dialogue A }
$$

$a^{\prime}$.
Differences

2. How does Yuka try to be polite making requests?

\section{Appendix C}

OPDCT

Direction: Read each of the situations. After each situation write what you would say in the situation in a normal conversation. This situation is analysed as [+imposition], [.power], [+distance], where [+] means "more" and [.] means "less."

You are writing a difficult paper for Professor Hill. You need some help with the paper but Professor Hill is away for a month. A friend of yours has suggested you go and see Professor Watson. Although you do not know Professor Watson and Professor Watson is extremely busy, you have decided to ask Professor Watson to look through your long paper before you hand it in the next day. What would you ask Professor Watson? (based on Takahashi, 1998, 2001)

You: 
Direction: There are 20 role-plays. You will be given a role-card before each of the role-plays. The role-card will describe the situation and your role (Role B). Read the situation described on the first card. It will require you to ask for something from the native speaker so you will have to start the role-play. The native speaker may or may not respond. This situation is analysed as [+imposition], [power], [+distance], where [+] means "more", [.] means "less," and [ \pm ] means "equal."

You must write an essay on a topic and turn it in by tomorrow. You have just found a very long interesting article on the topic, but it is written in Chinese. You can't read the article in Chinese and you need to translate it into Japanese. You have just heard that there is a student in another department who is bilingual in Chinese and Japanese. Although you have never spoken to the student before, you decide to ask the student to translate the article into Japanese. (based on Hill, 1997)

Now: You see the student.

LT

Direction: Read each of the following situations and after each situation listen to a conversation between Taro (a Japanese university student) and an interlocutor (a native speaker of English) in the situation and then score the appropriateness of Taro's request on 5-point scale. This situation is analysed as [+imposition], [.power], [+distance], where [+] means "more" and [.] means "less."

Taro is working in a restaurant. The owner has asked Taro to get each customer to complete a very long questionnaire about the quality of the food and the service in the restaurant. Taro has given the questionnaire to a customer. Taro notices that the customer has not filled it in but is about to leave in a hurry. Taro needs to have the questionnaire filled by the customer. (based on Hudson et al., 1992, 1995)

Taro: Excuse me. I can see you are in a hurry. But please fill in this questionnaire. Brown: Oh, look. I'm sorry I really haven't got the time.

not appropriate at all $1-2-3-4-5$ completely appropriate

AJT

Direction: Read each of the situations. After each situation you will be presented with three possible responses. Score the first possible response on 11-point scale and score subsequent responses with proportionally higher or lower number in accordance with response's degree of acceptability. This situation is analysed as [+imposition], [.power], [+distance], where [+] means "more" and [.] means "less."

Professor King at your university is a famous psychologist. You are now reading one of Professor King's books and finding it very complicated. You would like to ask Professor King some questions about the book. Professor King does not know you and Professor King is extremely busy. However, you decide to go and ask Professor King to spare you some time for some questions. What would you ask Professor King? (based on Takahashi, 1998, 2001)

a: I want to ask you some questions.

not appropriate at all $0-1-2-3-4-5-6-7-8-9-10$ completely appropriate b: I was wondering if it would be possible for me to ask you some questions. not appropriate at all $0-1-2-3-4-5-6-7-8-9-10$ completely appropriate c: Could I possibly ask you some questions?

not appropriate at all $0-1-2-3-4-5-6-7-8-9-10$ completely appropriate 